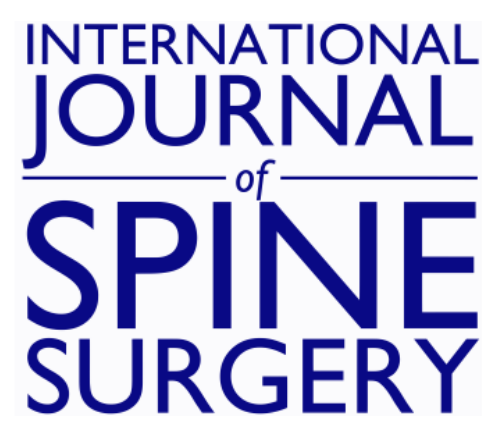

\title{
Three- and 4-Level Lumbar Arthrodesis Using Adjunctive Pulsed Electromagnetic Field Stimulation: A Multicenter Retrospective Evaluation of Fusion Rates and a Review of the Literature
}

Vikas V. Patel, James Billys, David O. Okonkwo, David Y. He, James T. Ryaby and Kris Radcliff

Int J Spine Surg 2021, 15 (2) 228-233

doi: https://doi.org/10.14444/8031

http://ijssurgery.com/content/15/2/228

This information is current as of April 26, 2023.

Email Alerts Receive free email-alerts when new articles cite this article. Sign up at:

http://ijssurgery.com/alerts

The International Journal of Spine Surgery

2397 Waterbury Circle, Suite 1,

Aurora, IL 60504, Phone: +1-630-375-1432 


\title{
Three- and 4-Level Lumbar Arthrodesis Using Adjunctive Pulsed Electromagnetic Field Stimulation: A Multicenter Retrospective Evaluation of Fusion Rates and a Review of the Literature
}

\author{
VIKAS V. PATEL, ${ }^{1}$ JAMES BILLYS, ${ }^{2}$ DAVID O. OKONKWO,${ }^{3}$ DAVID Y. HE, ${ }^{4}$ JAMES T. RYABY,${ }^{5}$ KRIS \\ RADCLIFF $^{6}$ \\ ${ }^{I}$ Department of Orthopedics, University of Colorado Anschutz Medical Campus, Aurora, Colorado, ${ }^{2}$ The Back Center, Melbourne, Florida, ${ }^{3}$ University of \\ Pittsburgh, Pittsburgh, Pennsylvania, ${ }^{4}$ Analytical Solutions Group, Inc, North Potomac, Maryland, ${ }^{5}$ Orthofix, Inc, Lewisville, Texas, ${ }^{6}$ Rothman Institute, Egg \\ Harbor Township, New Jersey
}

\begin{abstract}
Background: The incidence of 3- and 4-level lumbar arthrodesis is rising due to an aging population, and fusion rates affect clinical success in this population. Pulsed electromagnetic field (PEMF) stimulation is used as an adjunct to increase fusion rates following multilevel arthrodesis. The purpose of the study was to evaluate the fusion rates for subjects who underwent 3- and 4-level lumbar interbody arthrodesis following PEMF treatment.

Methods: In this retrospective, multicenter study, patient charts that listed 3- or 4-level lumbar arthrodesis with adjunctive use of a PEMF device were evaluated. Inclusion criteria included patients who were diagnosed with lumbar degenerative disease, spinal stenosis, and/or spondylolisthesis (grade 1 or 2). A radiographic evaluation of fusion status was performed at 12 months by the treating physicians. Fusion rates were stratified by graft material, surgical interbody approach, and certain clinical risk factors for pseudoarthrosis.

Results: A total of 55 patients were identified who had a 12-month follow-up. The radiographic fusion rate was $92.7 \%$ (51 patients) at 12 months. There were no significant differences in fusion rates for patients treated with allograft or autograft, for patients with different interbody approaches, or for those with or without certain clinical risk factors.

Conclusions: With modern fusion techniques and PEMF, the overall fusion rate was high following 3- and 4-level lumbar arthrodesis.

Level of Evidence: 4.

Clinical Relevance: PEMF may be a useful adjunct for treatment of patients with surgical risk factors, such as multilevel arthrodesis, and clinical risk factors.

Lumbar Spine

Keywords: pulsed electromagnetic field stimulation, lumbar arthrodesis, adjunctive therapy, spinal fusion, bone stimulation, lumbar fusion, pseudarthrosis, failed fusion
\end{abstract}

\section{INTRODUCTION}

Due to increases in life expectancy and health longevity, the incidence of degenerative lumbar disease is rising, and the frequency of multilevel arthrodesis is correspondingly higher. ${ }^{1}$ Arthrodesis of at least 3 levels is a risk factor for significantly lower fusion rates. ${ }^{2}$ Higher pseudoarthrosis rates are associated with worse clinical outcomes. ${ }^{3}$ In addition, if fusion fails, patient disability increases, return-to-work rates fall, and pain-medication usage increases. ${ }^{4}$ Furthermore, certain risk factors including diabetes, obesity, tobacco use, advanced age, and osteoporosis have been linked to higher rates of nonunion or delayed union, inhibition of bone repair, and/or higher complication rates. ${ }^{5-14}$ Given these challenges, adjunctive measures are often recommended to mitigate the risk of pseudoarthrosis. $^{11}$

One such adjunctive measure that has been demonstrated to improve bone healing in procedures including fracture repair and spinal arthrodesis is pulsed electromagnetic field (PEMF) stimulation. ${ }^{15-21}$ Specifically, in a randomized, controlled clinical trial of PEMF for anterior cervical discectomy and fusion (ACDF), PEMF significantly improved the fusion rate in smokers and in participant who received multilevel arthrod- 
esis as compared with controls who did not receive PEMF treatment. ${ }^{20}$ Similarly, in a double-blind, randomized, placebo controlled study, adjunctive PEMF treatment resulted in significantly increased fusion rates compared with placebo treatment after primary posterolateral lumbar spinal fusion at 1 or 2 levels. ${ }^{17}$

Although these level 1 studies convincingly demonstrate increased fusion rates resulting from adjunctive PEMF treatment, they do not describe fusion rates after lumbar interbody arthrodesis of 3 and 4 levels. Furthermore, the participants enrolled in those Food and Drug Administration (FDA) studies may not represent everyday patients seen in clinical practice, such as those with clinical risk factors including diabetes, advanced age, tobacco use, obesity, and osteoporosis.

The primary aim of this study was to retrospectively evaluate the fusion rate of adjunctive PEMF stimulation following lumbar 3- and 4-level arthrodesis. The secondary aim was to assess fusion rates between patients with and those without risk factors for pseudoarthrosis. A retrospective study was performed on a population of patients requiring a variety of lumbar interbody arthrodeses to evaluate fusion rate outcomes.

\section{METHODS}

\section{Aims and Study Design}

The primary aim of this study was to retrospectively evaluate fusion rates of 3- and 4-level lumbar arthrodeses that were performed with the adjunctive use of PEMF stimulation; a secondary aim was to assess fusion rates between patients with and without certain demographic risk factors for pseudoarthrosis.

A retrospective, multicenter, open-label study using the Spinal-Stim device (Orthofix, Inc, Lewisville, TX) was performed with patients undergoing lumbar arthrodesis. Institutional review boards at each institution approved the study and waived the requirement for informed consent (WIRB No. 20152038; COMIRB No. 15-1496; ARMC No. 15042).

Patients were enrolled at 5 institutions and were included in the study if they had undergone 3- or 4level lumbar interbody arthrodesis with adjunctive use of the Spinal-Stim device (Orthofix), which was designed specifically for the lumbar spine. In addition, participants were required to be at least
18 years of age and have been diagnosed with lumbar degenerative disease, spinal stenosis, and/or spondylolisthesis (grade 1 or 2). Participants were also required to have a fusion assessment at 12 months either radiographically or by computed tomography (CT) scan. Potential participants were excluded from the study if they solely had posterolateral fusion (without interbody cages); had significant lumbar instability, defined as sagittal or coronal plane listhesis greater than grade 2 spondylolisthesis; had scoliosis greater than $30^{\circ}$; had surgery due to traumatic injury; had a body mass index (BMI) of $>40$; or had an overt or active bacterial infection, either local or systemic, during the 12-month postoperative period. There were no restrictions placed on the surgical approach, fixation, graft material, or postoperative care regimen. Surgeries were performed between January 2010 and March 2015.

\section{PEMF Device}

Spinal-Stim (Orthofix) is a Class III commercial electromagnetic field device approved by the FDA for osteogenesis stimulation. Specifically, it has been approved as an adjunct for lumbar spine fusion surgery in patients at high risk for nonfusion. The device consists of a single coil placed posteriorly to the spine covering all lumbar levels. ${ }^{22}$

\section{End Points}

The primary end point was the treating surgeon's assessment of fusion status at 12 months as determined by the presence of continuous bridging bone by plain films or CT. Twelve months was the latest follow-up time that was common at all sites. Information on revisions that occurred postoperatively and after PEMF treatment were also collected.

\section{Statistical Analysis}

Descriptive statistics were provided for both clinical and surgical risk factors and demographic parameters. In the comparison of 12-month fusion status by risk and surgical factors, the Fisher exact test was used for binary variables. Exact $\chi^{2}$ test was used if there were more than 2 categories. The significance level for all statistical tests was set at a 2 -sided $P$ value of less than .05 . No adjustment for multiple comparisons was made. Due to the high fusion rate, logistic regression was not performed. 
Table 1. Demographic frequency.

\begin{tabular}{|c|c|c|}
\hline Demographic & n & $\%$ \\
\hline \multicolumn{3}{|l|}{ Age, y } \\
\hline$<65$ & 32 & 58 \\
\hline $65+$ & 23 & 42 \\
\hline \multicolumn{3}{|l|}{ Gender } \\
\hline Female & 35 & 64 \\
\hline Male & 20 & 36 \\
\hline \multicolumn{3}{|l|}{ Weight status (BMI) } \\
\hline Underweight $(<18.5)$ & 1 & 2 \\
\hline Normal weight (18.5-24.99) & 10 & 18 \\
\hline Overweight (25-29.99) & 24 & 44 \\
\hline Obese $(30-39.99)$ & 20 & 36 \\
\hline \multicolumn{3}{|l|}{ Race } \\
\hline Unknown/undisclosed & 10 & 18 \\
\hline Black or African American & 1 & 2 \\
\hline White & 43 & 78 \\
\hline Asian & 1 & 2 \\
\hline \multicolumn{3}{|l|}{ Nicotine use at time of surgery } \\
\hline Yes & 9 & 24 \\
\hline No & 29 & 76 \\
\hline \multicolumn{3}{|l|}{ Diabetes diagnosis } \\
\hline Yes & 9 & 16 \\
\hline No & 46 & 84 \\
\hline \multicolumn{3}{|l|}{ Osteoporosis diagnosis } \\
\hline Yes & 6 & 11 \\
\hline No & 49 & 89 \\
\hline \multicolumn{3}{|l|}{ Prior failed lumbar fusion } \\
\hline Yes & 4 & 11 \\
\hline No & 34 & 89 \\
\hline \multicolumn{3}{|l|}{ Indications for Surgery } \\
\hline DDD & 36 & ${ }^{\mathrm{a}}$ \\
\hline Stenosis & 45 & $\mathrm{-}^{\mathrm{a}}$ \\
\hline Spondylolisthesis & 11 & $\mathrm{~L}^{\mathrm{a}}$ \\
\hline Scoliosis (including kyphoscoliosis) & 6 & - $^{\mathrm{a}}$ \\
\hline
\end{tabular}

Abbreviations: BMI, body mass index; DDD, degenerative disc disease.

${ }^{\mathrm{a}}$ Multiple indications per patient.

\section{RESULTS}

There were 55 patients and 186 surgical levels enrolled in the study, and all patients underwent a 3or 4- level arthrodesis.

\section{Demographics and Surgical Factors}

Of the 55 participants, the mean age was 62.2 years and the range was $29-80$ years. The demographics and risk factors varied across the participant population (Table 1). In addition to the multilevel surgical risk factor for pseudoarthrosis, the next largest single risk factor was for patients who were overweight (BMI, 25-29.9) or obese (3039.9; both categories totaled $80 \%$ of participants). The majority of patients were treated for stenosis and/or degenerative disc disease (Table 1). Threelevel arthrodesis, levels L3-L4 and L4-L5 (100\% of participants) and anterior lumbar interbody fusion (ALIF) and posterior lateral interbody fusion (PLIF; each representing $44 \%$ of patients) were most common (Tables 2 and 3).
Table 2. Surgical factor frequency.

\begin{tabular}{llr}
\hline Surgical Factor & n & \% \\
\hline Number of levels & & \\
3 & 34 & 62 \\
4 & 21 & 38 \\
Levels $^{\text {a }}$ & & \\
L2-L3 & 40 & 73 \\
L3-L4 & 55 & 100 \\
L4-L5 & 55 & 100 \\
L5-S1 & 36 & 65
\end{tabular}

${ }^{\mathrm{a}} \mathrm{A}$ total of 186 levels were treated.

\section{Fusion Outcomes}

The overall fusion rate was $92.7 \%(51 / 55$ patients), which was determined by x-ray $(69.1 \%)$, CT $(20.0 \%)$, or MRI $(1.8 \%)$. In $9.1 \%$ of patients, the imaging modality was not specified. There were 2 revision surgeries, 1 which was attributed to breakage of instrumentation and the other for pedicle subtraction osteotomy and hardware removal. The fusion rate for patients with risk factors for pseudoarthrosis that included high-weight status, nicotine use, a diagnosis of osteoporosis or diabetes, a prior pseudoarthrosis, a multilevel

Table 3. Fusion rate for subpopulations.

\begin{tabular}{|c|c|c|c|}
\hline & N Fused/Total & $\%$ Fused & $P$ Value \\
\hline All subjects & $51 / 55$ & 92.7 & NA \\
\hline Age, y & & & 1.0 \\
\hline$<65$ & $30 / 32$ & 93.8 & \\
\hline $65+$ & $21 / 23$ & 91.3 & \\
\hline Weight status (BMI) & & & .17 \\
\hline Underweight or normal weight & $9 / 11$ & 81.8 & \\
\hline Overweight or obese & $42 / 44$ & 95.5 & \\
\hline Nicotine use at time of surgery & & & 1.00 \\
\hline Yes & $8 / 9$ & 88.9 & \\
\hline No & $27 / 29$ & 93.1 & \\
\hline Diabetes diagnosis & & & 1.00 \\
\hline Yes & $9 / 9$ & 100.0 & \\
\hline No & $42 / 46$ & 91.3 & \\
\hline Osteoporosis diagnosis & & & 1.00 \\
\hline Yes & $6 / 6$ & 100.0 & \\
\hline No & $45 / 49$ & 91.8 & \\
\hline Prior failed lumbar fusion & & & 1.00 \\
\hline Yes & $4 / 4$ & 100.0 & \\
\hline No & $33 / 34$ & 97.1 & \\
\hline Arthrodesis levels & & & .64 \\
\hline 3 & $32 / 34$ & 94.1 & \\
\hline 4 & $19 / 21$ & 90.5 & \\
\hline Surgical approach & & & .60 \\
\hline Lateral & $4 / 4$ & 100.0 & \\
\hline ALIF & $21 / 24$ & 87.5 & \\
\hline PLIF & $23 / 24$ & 95.8 & \\
\hline Other & $3 / 3$ & 100.0 & \\
\hline Surgical approach & & & 1.00 \\
\hline Minimally invasive & $42 / 46$ & 91.3 & \\
\hline Open & $9 / 9$ & 100.0 & \\
\hline Graft material & & & .86 \\
\hline Allograft & $26 / 28$ & 92.9 & \\
\hline Autograft & $21 / 23$ & 91.3 & \\
\hline Other (graft type not identified) & $3 / 3$ & 100.0 & \\
\hline
\end{tabular}

Abbreviations: ALIF, anterior lumbar interbody fusion; BMI, body mass index; NA, not applicable; PLIF, posterior lateral interbody fusion. 
Table 4. Multilevel interbody lumbar arthrodesis literature.

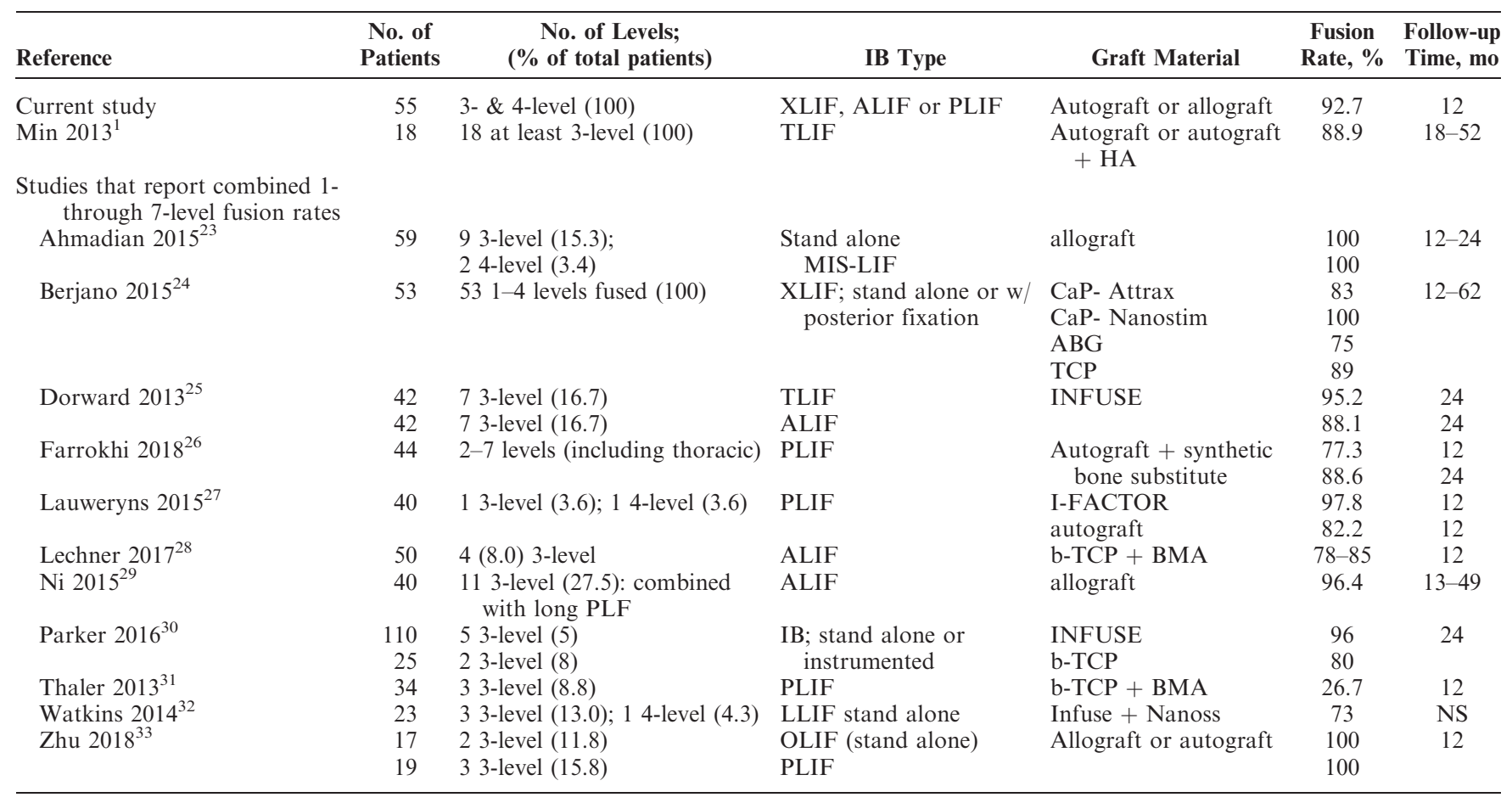

Abbreviations: ABG, autologous bone graft; ALIF, anterior lumbar interbody fusion; BMA, bone marrow aspirate; CaP, calcium phosphate; HA, hydroxyapatite; IB, interbody; LIF, lumbar interbody fusion ; LLIF, lateral lumbar interbody fusion; MIS, minimally invasive surgery; NS, not stated; OLIF, oblique lateral interbody fusion; PLF, posterolateral fusion; PLIF, posterior lateral interbody fusion; TCP, tricalcium phosphate; TLIF, transforaminal lumbar interbody fusion; XLIF, extreme lumbar interbody fusion.

arthrodesis, or at least 2 of the aforementioned risk factors resulted in fusion rates ranging from $90.5 \%-$ $100 \%$ (Table 3). A comparison between patients with risk factors as compared with those without risk factors showed no statistical differences (Table 3). In addition, the fusion rate for different surgical approaches such as extreme lumbar interbody fusion, transforaminal lumbar interbody fusion, and ALIF ranged from $87.5 \%-100 \%$, and for 3and 4-level arthrodesis the rates were $94.1 \%$ and $90.5 \%$, respectively, neither of which was statistically significant. Last, there was no significant difference in fusion rates between patients treated with allograft or autograft. Of note, there were no documented adverse events attributed to PEMF use.

\section{DISCUSSION}

In a multicenter cohort of patients undergoing 3and 4-level lumbar arthrodesis with adjunctive PEMF treatment, the incidence of fusion at 12 months was $92.7 \%$, and there were no significant differences between participants with and those without clinical risk factors.

As a comparator for fusion rates in the absence of PEMF, a literature search was performed for publications that described 3- and 4-level lumbar interbody fusion rates. Twelve publications were identified (Table 4) that described a fusion rate ranging from $26.7 \%-100 \%$. One publication reported fusion rates separately for 3- and 4-level arthrodesis, ${ }^{1}$ whereas all others reported a combined fusion rate for single-level and multilevel interbody arthrodesis, which may have resulted in higher fusion rates than if multilevel fusion rates had been reported separately. ${ }^{1}$ To our knowledge, the number of patients in the current study comprises the largest population of 3 and 4 level lumbar fusions. Although the fusion rates of the current study falls within the range that is reported in the literature, a direct comparison is difficult due to the differences in number of arthrodesis levels, graft type used, and follow-up duration. The fusion assessment for the current study was performed at 12 months. Although this may be considered early by some to assess fusion, the literature review demonstrated that about $40 \%$ of reports evaluated fusion at 12 months.

The secondary aim of this study was to assess fusion rates between participants without and those with risk factors. Clinical factors, such as advanced age, nicotine use, and diabetes, have been demon- 
strated to increase the complication rate following lumbar arthrodesis. ${ }^{5,8,12}$ One potential complication is psuedoarthrosis, and recent publications confirm a positive correlation between clinical risk factors and pseudoarthrosis given that pseudoarthrosis rates were significantly higher in smokers, those of advanced age, and obese patients undergoing lumbar arthrodesis than in nonsmokers. ${ }^{13,14,34} \mathrm{In}$ the presence of PEMF stimulation, the current study demonstrated no significant differences in fusion rates between participants without and those with risk factors. Although this finding may indicate that PEMF increases the fusion rates for patients with these risk factors, the sample size is small and caution is warranted for interpretation. Appropriately powered randomized controlled studies are required.

The results of the current study concur with the findings of previous PEMF studies that demonstrate high fusion rates in the presence of surgical and clinical risk factors following spinal arthrodesis. The fusion rate following adjunctive PEMF stimulation for at least 3-level ACDF procedures for patients who had at least 1 additional risk factor for pseudoarthrosis was $97.3 \%-100 \%$ at 12 months, ${ }^{35}$ and PEMF significantly improved the fusion rate in smokers and in patients who received multilevel arthrodesis as compared with controls who did not receive PEMF treatment. ${ }^{20}$

Limitations of the current study include the lack of a concurrent control. This was a retrospective study that evaluated the standard clinical practice of 4 surgeons using PEMF for multilevel arthrodesis and no non-PEMF comparator was available. Another limitation is that the treating surgeon determined the fusion status, and surgeon bias is known with respect to consideration of other clinical outcome parameters. Also, retrospective studies have the potential for selection bias, and no assessment of patient accountability is possible with the data collected. However, data from all patients who met the inclusion and exclusion criteria were reported in this study. Certain risk factors for pseudoarthrosis such as at least grade 2 spondylolisthesis, scoliosis, trauma, being morbidly obese, and an active bacterial infection were excluded from the study, and thus the effect of PEMF on a population with these risk factors is unknown. Although PEMF was prescribed for 3-6 months, PEMF compliance was not measured.

\section{CONCLUSIONS}

The results of the current clinical evaluation suggest that PEMF treatment following 3- and 4level lumbar arthrodesis results in a high fusion rate despite risk factors.

\section{ACKNOWLEDGMENTS}

We acknowledge Brent L. Atkinson, PhD, of Atkinson Biologics Consulting for manuscript preparation, literature search, and data analysis.

\section{REFERENCES}

1. Min SH, Yoo JS. The clinical and radiological outcomes of multilevel minimally invasive transforaminal lumbar interbody fusion. Eur Spine J. 2013;22(5):1164-1172.

2. Inage K, Ohtori S, Koshi M, et al. One-, two-, three-level instrumented posterolateral fusion of the lumbar spine with a local bone graft: a prospective study with a 2-year follow-up. Spine. 2011;36(17):1392-1396.

3. Noshchenko A, Lindley EM, Burger EL, Cain CM, Patel $\mathrm{VV}$. What is the clinical relevance of radiographic nonunion after single-level lumbar interbody arthrodesis in degenerative disc disease? A meta-analysis of the YODA project database. Spine. 2016;41(1):9-17.

4. Mayer T, McMahon MJ, Gatchel R, et al. Socioeconomic outcomes of combined spine surgery and functional restoration in workers' compensation spinal disorders with matched controls. Spine. 1998;23(5):598-605.

5. Appaduray SP, Lo P. Effects of diabetes and smoking on lumbar spinal surgery outcomes. J Clin Neurosci. 2013;20(12):17131717.

6. Gan JC, Glazer PA. Electrical stimulation therapies for spinal fusions: current concepts. Eur Spine J. 2006;15:13011311.

7. Gaston MS, Simpson AHRW. Inhibition of fracture healing. J Bone Joint Surg Br. 2007;89-B:1553-1560.

8. Glassman SD, Alegre G, Carreon L, Dimar JR, Johnson JR. Perioperative complications of lumbar instrumentation and fusion in patients with diabetes mellitus. Spine J. 2003;3(6):496501.

9. Hilibrand AS, Fye MA, Emery SE, Palumbo MA, Bohlman HH. Impact of smoking on the outcome of anterior cervical arthrodesis with interbody or strut-grafting. $J$ Bone Joint Surg Am. 2001;83-A:668-673.

10. Lau D, Chou D, Ziewacz JE, Mummaneni PV. The effects of smoking on perioperative outcomes and pseudoarthrosis following anterior cervical corpectomy: clinical article. $J$ Neurosurg Spine. 2014;21(4):547-558.

11. Tang H, Zhu J, Ji F, Xie Y, Fei H. Risk factors for postoperative complication after spinal fusion and instrumentation in degenerative lumbar scoliosis patients. J Orthop Surg Res. 2014;9(1):9-15.

12. Ong KL, Auerbach JD, Lau E, Schmier J, Ochoa JA. Perioperative outcomes, complications, and costs associated with lumbar spinal fusion in older patients with spinal stenosis and spondylolisthesis. Neurosurg Focus. 2014;36(6):E5. 
13. Bydon M, De la Garza-Ramos R, et al. Impact of smoking on complication and pseudarthrosis rates after singleand 2-level posterolateral fusion of the lumbar spine. Spine. 2014;39(21):1765-1770.

14. Phan K, Rogers P, Rao PJ, Mobbs RJ. Influence of obesity on complications, clinical outcome, and subsidence after anterior lumbar interbody fusion (ALIF): prospective observational study. World Neurosurg. 2017;107:334-341.

15. Bose B. Outcomes after posterolateral lumbar fusion with instrumentation in patients treated with adjunctive pulsed electromagnetic field stimulation. Adv Ther. 2001;18:12-20.

16. Hannemann PF, Mommers EH, Schots JP, Brink PR, Poeze M. The effects of low-intensity pulsed ultrasound and pulsed electromagnetic fields bone growth stimulation in acute fractures: a systematic review and meta-analysis of randomized controlled trials. Arch Orthop Trauma Surg. 2014;134(8):10931106.

17. Linovitz RJ, Pathria M, Bernhardt M, et al. Combined magnetic fields accelerate and increase spine fusion: a doubleblind, randomized, placebo-controlled study. Spine. 2002;27(13):1383-1389.

18. Nelson FR, Brighton CT, Ryaby J, et al. Use of physical forces in bone healing. J Am Acad Orthop Surg. 2003;11:344354.

19. Ryaby JT. Clinical effects of electromagnetic and electric fields in fracture healing. Clin Ortho Rel Res. 1998;355(suppl):S205-S215.

20. Foley KT, Mroz, TE, Arnold PM, et al. Randomized, prospective, controlled clinical trial of pulsed electromagnetic field stimulation for cervical fusion. Spine J. 2008;8:436-442.

21. Garland DE, Moses B, Salyer W. Long-term follow-up of fracture nonunions treated with PEMFs. Contemp Orthop. 1991;22(3):295-302.

22. Waldorff EI, Zhang N, Ryaby JT. Pulsed electromagnetic field applications: a corporate perspective. J Orthop Translat. 2017;9:60-68.

23. Ahmadian A, Bach K, et al. Stand-alone minimally invasive lateral lumbar interbody fusion: multicenter clinical outcomes. J Clin Neurosci. 2015;22(4):740-746.

24. Berjano P, Langella F, Damilano M, et al. Fusion rate following extreme lateral lumbar interbody fusion. Eur Spine J. 2015;24(suppl 3):369-371.

25. Dorward IG, Lenke LG, Bridwell KH, et al. Transforaminal versus anterior lumbar interbody fusion in long deformity constructs: a matched cohort analysis. Spine. 2013;38(12):e755-e762.

26. Farrokhi MR, et al. Clinical outcomes of posterolateral fusion versus posterior lumbar interbody fusion in patients with lumbar spinal stenosis and degenerative instability. Pain Physician. 2018;21:383-406.

27. Lauweryns P, Raskin Y. Prospective analysis of a new bone graft in lumbar interbody fusion: results of a 2-year prospective clinical and radiological study. Int J Spine Surg. 2015;9(2). 2015 Feb 3;9:2.

28. Lechner R, Putzer D, Liebensteiner M, et al. Fusion rate and clinical outcome in anterior lumbar interbody fusion with beta-tricalcium phosphate and bone marrow aspirate as a bone graft substitute. A prospective clinical study in fifty patients. Int Orthop. 2017;41(2):333-339.

29. Ni J, Zheng Y, Liu N, et al. Radiological evaluation of anterior lumbar fusion using PEEK cages with adjacent vertebral autograft in spinal deformity long fusion cages. Eur Spine J. 2015;24(4):791-799.

30. Parker RM, Malham GM. Comparison of a calcium phosphate bone substitute with recombinant human bone morphogenetic protein-2: a prospective study of fusion rates, clinical outcomes and complications with 24-month follow-up. Eur Spine J. 2016;26(3):754-763.

31. Thaler M, Lechner R, Gstottner M, et al. The use of beta-tricalcium phosphate and bone marrow aspirate as a bone graft substitute in posterior lumbar interbody fusion. Eur Spine J. 2013;22(5):1173-1182.

32. Watkins R, Watkins R, Hanna R. Non-union rate with stand-alone lateral lumbar interbody fusion. Medicine. December 2014;93(29):e275.

33. Zhu G, Hao Y, et al. Comparing stand-alone oblique lumbar interbody fusion with posterior lumbar interbody fusion for revision of rostral adjacent segment disease. Medicine. 2018;97(40):e12680.

34. Wu CH, Kao YH, Yang SC, et al. Supplementary pedicle screw fixation in spinal fusion for degenerative spondylolisthesis in patients aged 65 and over. Acta Orthop. 2008;79:67-73.

35. Coric D, Bullard DE, Patel VV, et al. Pulsed electromagnetic field stimulation may improve fusion rates in cervical arthrodesis in high risk populations. Bone Joint Res. 2018;7(2):124-130.

Disclosures and COI: The study was funded by Orthofix. V.V.P., J.B., and D.O.O. received Orthofix funding to support clinical research. K.R. did not receive funding for this study from Orthofix. D.Y.H. is a consultant of Orthofix. J.T.R. is employed by and owns stock in Orthofix.

Corresponding Author: Kris Radcliff, Rothman Institute, 2500 English Creek Ave, Building 1300, Egg Harbor Township, NJ 08234. Phone: (800) 321-9999; Email: radcliffk@gmail.com.

Published 16 April 2021

This manuscript is generously published free of charge by ISASS, the International Society for the Advancement of Spine Surgery. Copyright (C) 2021 ISASS. To see more or order reprints or permissions, see http://ijssurgery.com. 